\title{
Disposable luciferase-based microfluidic chip for rapid assay of water pollution
}

Preprint for: https://doi.org/10.1002/bio.3508

\author{
Ivan Denisov*1, Kirill Lukyanenko ${ }^{1}$, Anton Yakimov ${ }^{1}$, \\ Igor Kukhtevich ${ }^{1}$, Elena Esimbekova ${ }^{1,2}$ and Peter Belobrov ${ }^{1}$ \\ ${ }^{1}$ Siberian Federal University, 660041, Krasnoyarsk, Russia \\ ${ }^{2}$ Institute of Biophysics SB RAS Federal Research Center \\ 'Krasnoyarsk Science Center SB RAS', Krasnoyarsk, Russia
}

June 22, 2018

\begin{abstract}
In the present study, we demonstrate a disposable luciferasebased microfluidic bioassay chip for environmental monitoring and methods for fabrication. The designed microfluidic system includes a chamber with immobilized enzymes of bioluminescent bacteria Photobacterium leiognathi and Vibrio fischeri and their substrates, which dissolve after introduction of water sample and thus activate bioluminescent reaction. Limits of detection for copper(II) sulfate, 1,3-dihydroxybenzene and 1,4-benzoquinone of the proposed microfluidic biosensor measured $3 \mu \mathrm{M}, 15 \mathrm{mM}$ and $2 \mu \mathrm{M}$ respectively, and these values are higher or close to the level of conventional environmental biosensors based on lyophilized bacteria. Approaches for entrapment of enzymes on poly(methyl methacrylate) (PMMA) plates using gelatin scaffold and solvent bonding of PMMA chip plates under room temperature were suggested. The proposed microfluidic system may be used with some available luminometers and future portable luminescence readers.
\end{abstract}

Keywords: bioassay; luciferase; microfluidics; lab-on-a-chip; solvent bonding

\section{Introduction}

Increasing human negative impact on water reservoirs [1] and soils [2,3] necessitate development of methods for environmental monitoring. Over the past 40 years, biosensors emerged as promising tools for rapid pollutant detection in

*E-mail: d.ivan.krsk@gmail.com 
different samples [4-6]. One of the major trends is to design biosensors suitable for point-of-care testing (POCT) [7], which has been extensively developed in the last decade [8, 9]. According to the POCT concept, assays should be performed on-site with the help of handheld devices [10]. Such devices offer cost-effective alternative to expensive and time-consuming laboratory tests.

Glucometers with plastic or paper strips represent the most known example of POC devices [11]. Some of POC devices use special systems with several wells for bioluminescent bacteria sensor [12]. Standart microwell plate can also be used for sample holding in POC devices [13]. There are POC electrochemical devices for lactat monitoring that use special patch from fibers [14]. Many POCT devices include built-in microfluidic chips, in which processes of sample preparation, fluid manipulation and detection are automated [15-17].

Electrochemical biosensors are one of the most common and commercially successful type of POCT devices [18,19]. In recent years there is a trend for using smartphones in point-of-care diagnostics [20|21]. This is due to their high prevalence and the ability to easily connect peripheral sensors. Smartphones became common tool for measuring the pulse [22] and they even can be used for cataract diagnostics [23]. However the sensitivity of smartphone's camera limits their application for POC diagnostics.

Different types of biosensor detection systems can be used for determination of pollutants in water samples; however, the most suitable are opticalbased biosensors [24-26]. Optical-based biosensors feature comparatively high sensitivity and provide real-time qualitative analysis without extensive sample preparation. Studies proposed that bioluminescence-based biosensors [27, 28] possess potential to become cost-effective and compact optical biosensors. In most cases, such bioluminescence-based bioassays use lyophilized wild-type or engineered bioluminescent bacteria [29-31]. However, the use of bacteria for such purposes presents several problems: strict storage conditions, low shelf life of encapsulated bacteria and drift of bacterial metabolism [32].

Enzymes extracted from luminous bacteria [33] can overcome these limitations. In bioassays, replacement of living organisms with enzyme preparations substantially increases reliability and simplifies the bioluminescent test procedure [34,35], easing automation of assay reactions in microdevices. Bioluminescent enzyme system consists of $\mathrm{NAD}(\mathrm{P}) \mathrm{H}: \mathrm{FMN}$-oxidoreductase and a luciferase emitting light at $490 \mathrm{~nm}$ in the presence of $F M N, N A D(P) H$, a long-chain aliphatic aldehyde and molecular oxygen (Fig. 11) [36]. Interaction of toxicants with enzymes of bacterial bioluminescent system leads to changes in measured light emission kinetics [37]. Such bioassays based on coupled enzyme bioluminescent system were developed for environmental monitoring and medical diagnostics [34]. Enzymatic assay is sutable for detection of quinones and phenols [39], salts of heavy metals [40], carbon nanoparticles [41] pesticides [38] and other [42]. Pollutants of different classes exert specific influence on kinetics of bioluminescence emission [43], allowing their differentiation by means of automated kinetic analysis [44].

To design biosensors based on coupled enzyme system NAD(P)H:FMNoxidoreductase and bacterial luciferase, stability of reagents must first be increased during storage, whereas measurement operations must be simplified. Among different methods of bioluminescent system immobilization [45-47] immobilization by entrapment of enzymes into gels has been found the most suitable for stabilization of bioluminescent enzyme system [48, 49]. An effective 


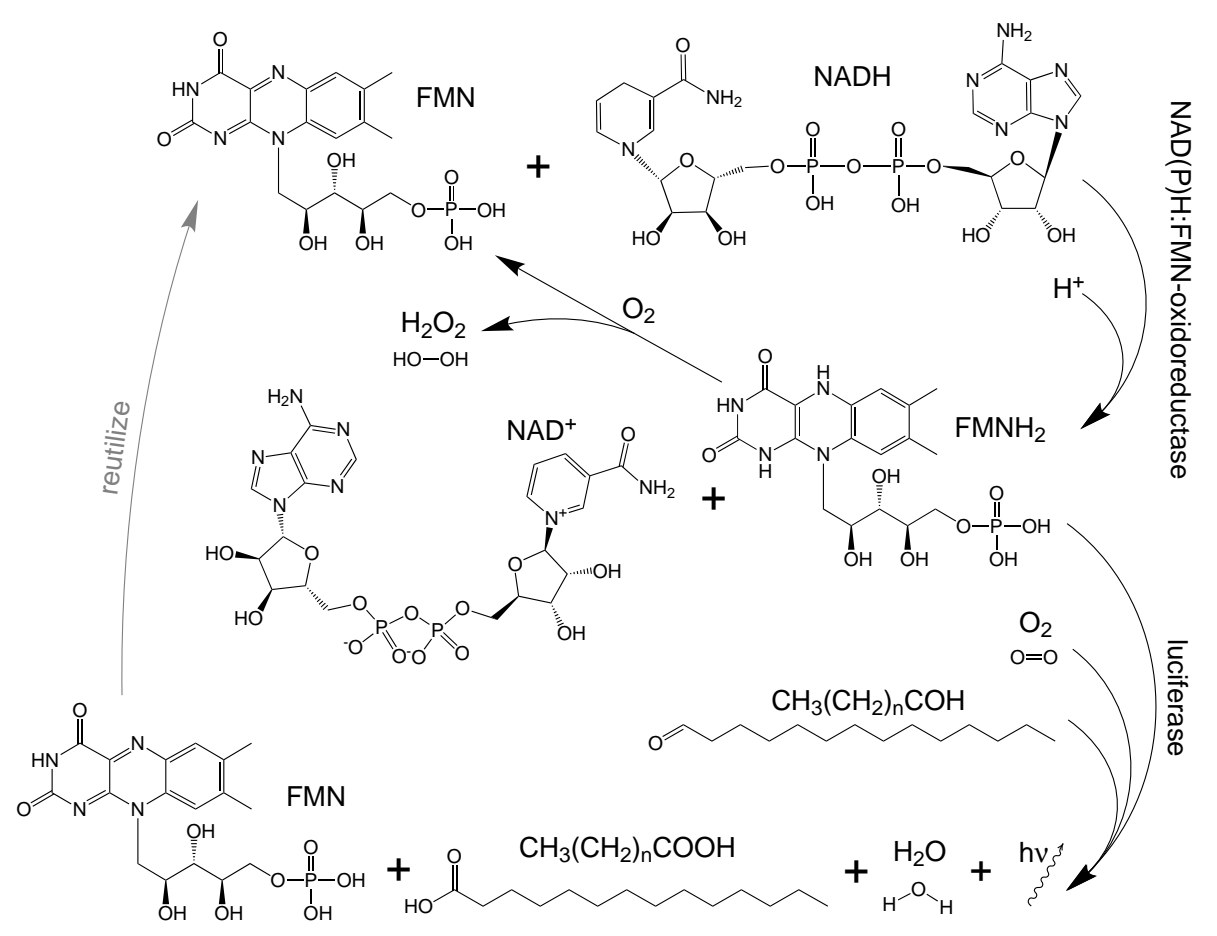

Figure 1: Scheme of enzymatic bioluminescent reaction: luciferase catalyzes oxidation of long-chain aliphatic aldehydes involving reduced flavin mononucleotide (FMN). One of the products of this reaction is a quantum of light $(h \nu)$ in the blue-green spectrum. To provide luciferase with reduced FMN $\left(\mathrm{FMNH}_{2}\right)$, luciferase reaction is coupled with $F M N$ reduction reaction catalyzed by $\mathrm{NAD}(\mathrm{P}) \mathrm{H}: \mathrm{FMN}$-oxidoreductase

method was also developed for co-immobilization of enzymes (NAD(P)H:FMNoxidoreductase and luciferase) and their substrates (NADH and aldehyde) into gels [50-52]. The method deals with immobilization of enzymes in starch or gelatin-based matrix, which is eventually dried in form of droplets on an inert surface.

Stable enzymes for disposable microfluidic chips (cartridgies) are also required for POCT-based biosensor design [53,54]. Elastomers and plastics are the most widespread and popular for microfluidic chip fabrication because they are easily accessible and inexpensive [55-57]. Polydimethylsiloxane (PDMS) is one of the most popular elastomer material for microfluidics [58,59]. However, this compound is unsuitable for use in the current work, because it requires thermal treatment to bond chip plates. Heat treatment can inactivate enzymes, which will ultimately hamper the assay. Thermoplastics are promising alternative to elastomers as they allow inexpensive mass production of chips, and most are compatible for performing assays that utilize biological and chemical reagents [60, 61]. PMMA was selected for the current work because it provides optical transparency and biocompatibility and allows construction of laboratory-scale prototypes using micro-milling method [62] or hot embossing [63]. Solvent and thermal diffusion bonding are the two most commonly 
used methods for bonding plastic chip plates [64]. However, heating will cause enzyme denaturation. Furthermore, tensile strength of solvent-bonded PMMA chips is five to ten times higher than those of thermally bonded ones, forming a much more durable bonded PMMA chips [65]. A neutral solvent that remain harmless to enzymes and their substrates must also be elected.

The present research aimed to develop and design a luciferase-based disposable microfluidic chip for water pollution testing. Optimal parameters for chip fabrication were also investigated in this study.

\section{Experimental}

\section{Reagents}

The following reagents were used: FMN (CHEBI:17621, Serva, Germany), reduced nicotinamide adenine dinucleotide (NADH) (CHEBI:16908, Gerbu, Germany), ethanol (CHEBI:16236, Merk, Germany), tetradecanal (CHEBI:84067, Merck, Germany), starch from potato (CHEBI:28017, Sigma-Aldrich, USA), gelatin from porcine skin (CHEBI:5291, Sigma-Aldrich, USA), potassium phosphate buffer with pH 7.0 (CHEBI:63036, Fluka, Sweden), PMMA (CHEBI:61369, SoftPlast, Russia), 1,2-dichloroethane (Soyuzhimprom, Russia) and acetone (Vekton, Russia). Lyophilized preparations of purified enzymes were produced at the Laboratory of Nanobiotechnology and Bioluminescence of the Institute of Biophysics SB RAS (Krasnoyarsk, Russia). One vial of preparation contained $0.5 \mathrm{mg}$ of luciferase EC 1.14.14.3 (Photobacterium leiognathi) from recombinant strain of Escherichia coli and 0.18 activity units of NAD(P)H:FMNoxidoreductase EC 1.5.1.29 (Vibrio fischeri).

\section{Instruments}

A computer numerical control milling machine Modela MDX-40A (Roland, Japan) was used to fabricate microchannels. A compressed air cylinder (Comozzi, Italy) was used to set pressure. A vacuum mixer (Averon, Russia) was used for mixing suspensions. Intensity of bioluminescent signal was measured by GloMax 20/20 luminometer (Promega, USA) using the mode for kinetic measurement. Images for analysis of FMN diffusion were obtained with Axio Scope.A1 microscope (Zeiss, Germany) equipped with digital camera AxioCam ICc 5 (Zeiss, Germany).

\section{Methods}

Channels in PMMA were constructed using micro-milling method [62] through sequential removal of the material's thin layers until formation of the desired geometry. Optimization of chip geometry and simulation of FMN release from dried starch gel was performed with COMSOL Multiphysics (COMSOL, Sweden). The model of optimized chip was designed by means of Solidworks (Dassault Systems SolidWorks Corp., France).

One vial of lyophilized preparations of purified enzymes was diluted in $500 \mu 1$ of phosphate buffer with $\mathrm{pH}$. Enzymes were immobilized in starch gel using the technique reported earlier [51,52]. In brief, $25 \mathrm{ml}$ of $3.15 \%$ aqueous starch 
suspension was heated until complete dissolution and then cooled until $25^{\circ} \mathrm{C}$. One vial of lyophilized preparations of purified enzymes was diluted in $500 \mu l$ of phosphate buffer at $\mathrm{pH}$. Thereafter, $380 \mu \mathrm{l}$ of lyophilized preparations with bacterial luciferase and NAD(P)H:FMN-oxidoreductase, $185 \mu 116 \mathrm{mM}$ of NADH and $585 \mu \mathrm{l}$ of $0.038 \%$ tetradecanal were consistently added to the suspension and mixed. Then, the suspension was dosed to the target surface for drying.

Enzymes and substrates of the bioluminescent system were immobilized in the reaction chamber of approximately $40 \mathrm{~mm}^{2}$ in two separate droplets of starch gel on the gelatin scaffold (Fig. 3). The first droplet of $10 \mu \mathrm{l}$ volume contained enzymes (NAD(P)H:FMN-oxidoreductase and luciferase) and their substrates (aldehyde and $\mathrm{NADH}$ ). The second one was $5 \mu \mathrm{l}$ droplet which contained immobilized FMN for reaction activation. Chips were dried for $24 \mathrm{~h}$ at $+8^{\circ} \mathrm{C}$ and sealed. After introducing analyzed sample, reagents were dissolved from gel and mixed, thus starting bioluminescent reaction.

Sealing of PMMA plates was performed using solvent bonding technique. Flash spraying of solvent for $20 \mathrm{~ms}$ on the surface of one PMMA cover plate was followed by mating to another plate with channelized surface and immobilized enzymes at the $30 \mathrm{~kg} / \mathrm{cm}^{2}$ pressure for $30 \mathrm{~s}$.

An electromechanical membrane and active mixing mode were used to induce uniform distribution of FMN in the reaction chamber after introduction of water sample into the chip. This technique was previously described in detail [66]. In brief, the membrane was connected to the input of inlet channel of the chip. The signal pattern for membrane movement was generated by a laboratory self-made device. This device consisted of LPC2103 MCU (NXP, Netherlands) and several optrons and transistors which controlled the $\mathrm{H}$ bridge, allowing application of voltage across the membrane in either direction. Signals were programmed and sent to an amplifier by the software made with BlackBox Component Builder (Oberon microsystems Inc, Switzerland). Membrane oscillations with predefined patterns created acoustic wave, which led to fluid movement in the chip.

Light intensity from bioluminescent reaction was measured in the reaction chamber of disposable chip. At the beginning, the chip was filled with $35 \mu 1$ of water sample. After sample introduction, the mixer was connected to the inlet of chip by silicon capillary (Fig. 2). The chip with attached mixer was placed in the luminometer on top of the photomultiplier tube aperture, and mixing was started inside luminometer $30 \mathrm{~s}$ after sample introduction. Kinetics measurement was started manually several seconds before mixing.

Values of control luminescence intensity of the enzyme system $\left(I_{c}\right)$ were obtained using distilled water samples. Model pollutants were dissolved in distilled water and used to evaluate sensitivity of bioassay. Residual luminescence was calculated according to the formula $\left(I_{\text {exp }} / I_{c}\right) \cdot 100 \%$, where $I_{\text {exp }}$ is luminescence intensity in the presence of analyzed sample with model pollutant. This formula shows the inhibitory effect of pollutant on the coupled enzyme system immobilized in the chip. Values of inhibition parameter $I C_{50}$, which is the concentration of pollutants causing system inhibition by $50 \%$, and limit of detection (LOD) were determined.

FMN distribution in the reaction chamber of the microfluidic chip was measured by means of hue, saturation and value (HSV) palette analysis of microscopy images acquired by Vimba SDK (Allied Vision, Netherlands). Images were processed using a software developed with BlackBox Component Builder (Oberon microsystems AG, Switzerland) utilising the FreeImage open-source 


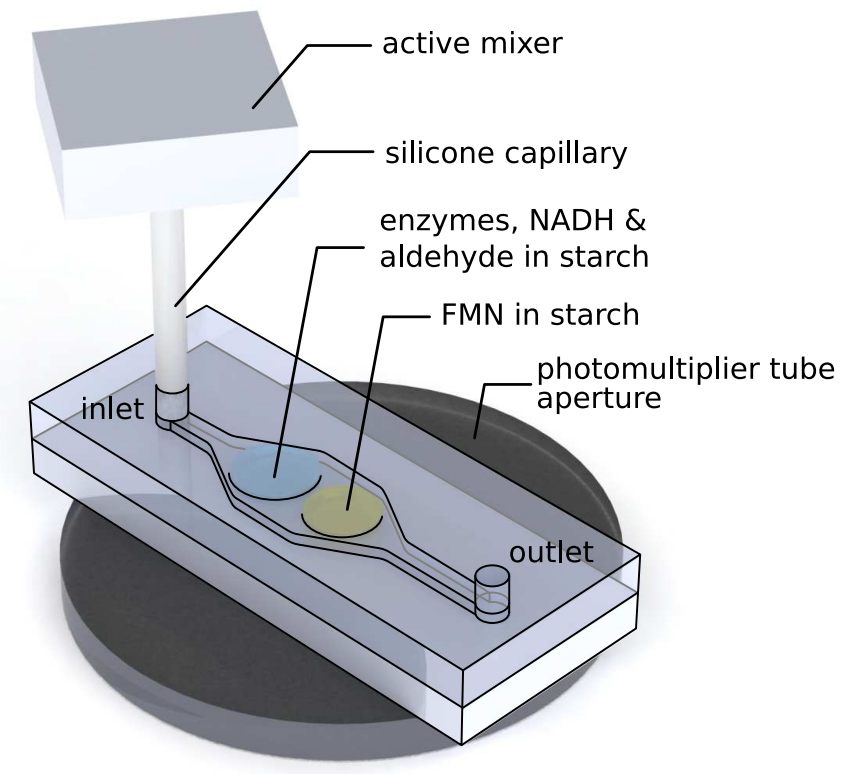

Figure 2: Scheme of chip experiments. Active mixer was attached to the inlet hole of the chip after reagent filled the reaction chamber. Then, the chip was placed on the top of photomultiplier aperture for measurement of bioluminescence kinetics. Reagents were mixed $30 \mathrm{~s}$ after sample introduction

lib.

Statistical analysis was performed using t-distribution at a 95\% range.

\section{Results and discussions}

\section{Construction of microfluidic chip}

The disposable enzymatic microfluidic chip (Fig. 3) consisted of a PMMA body with immobilized enzymes and substrates of bioluminescent reaction. The body of the chip was made from two PMMA plates measuring $11 \times 27 \mathrm{~mm}^{2}$ each. The first one was channelized by micro-milling, and the second was used as cover plate for sealing. The channelized plate comprised an inlet channel, a reaction chamber with reagents split in two parts and an outlet channel. Length of outlet channel was twice that of inlet channel.

Notably, luminescence intensity of immobilized bioluminescent system in the chip was less than that for enzymes immobilized on fluoroplastic film according to the technique described in [51]. Reduced bioluminescence resulted from the interaction of contaminating compounds contained in PMMA with enzymes and substrates during starch gel drying. To prevent this negative effect, the surface of reaction chamber was pre-coated with gelatin. After drying, gelatin formed a film on PMMA surface, and we used it as scaffold for introducing starch gel with enzymes and substrates. As a result, intensity of bioluminescence 


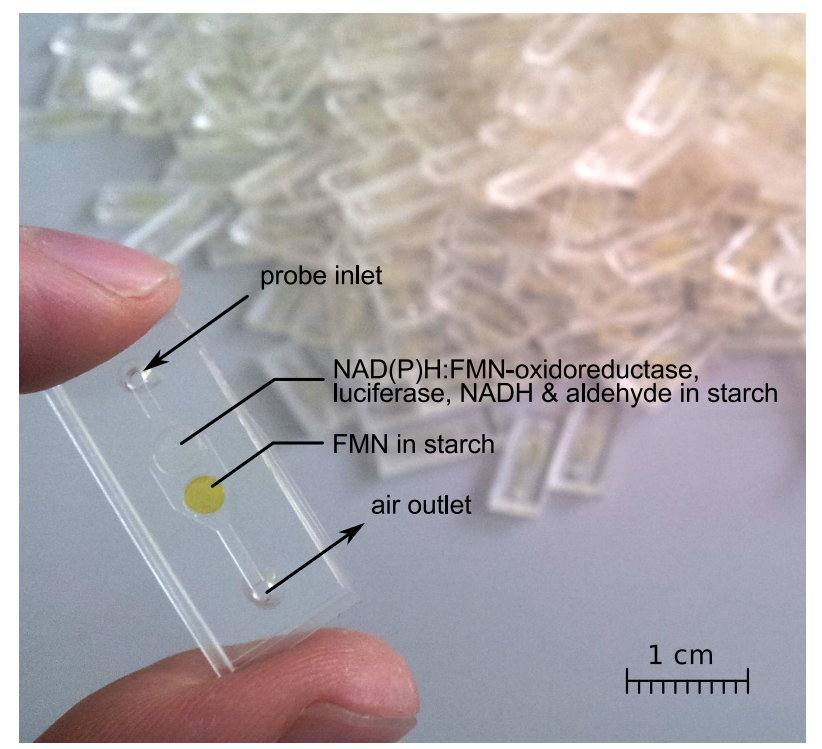

Figure 3: Disposable microfluidic chip for bioassay based on bioluminescent coupled enzyme system of luminous bacteria. The reaction chamber contained two dried droplets of starch gel: the first one contained NADH, tetradecanal, luciferase and $\mathrm{NAD}(\mathrm{P}) \mathrm{H}: \mathrm{FMN}$-oxidoreductase; the second one contained FMN

increased by $150 \%$ with respect to chips without gelatin scaffold. Standard variation decreased approx. from $50 \%$ to $30 \%$.

To obtain high luminescence intensity and reproducibility results, uniform distribution of FMN must be achieved throughout the reaction chamber. Passive mixing of FMN with other reagents in the reaction chamber was ineffective due to lack of convection and low diffusion constants of reagents. The problem was solved by active mixing of FMN with other components of enzymatic reaction. The model of FMN diffusion and convection was proposed earlier [67]. According to this model, most of FMN was released from the gel after $30 \mathrm{~s}$, as confirmed experimentally (Fig. 4). Thus, the optimal time for reagents mixing in the chip was $30 \mathrm{~s}$ after sample introduction.

During our initial investigations [68], we have placed the starch gel droplet with FMN right after the inlet channel followed by the droplet with enzymes and substrates. However, given the premature activation of bioluminescence reaction, this position caused scattering of luminescence intensity at the beginning of measurement (Fig. 5, curve 1); this result can be explained by untimely transfer of FMN in the area of enzymes during sample introduction (Fig. 4, a).

Deviations in the beginning of measurement significantly reduced after switching positions of enzymes with FMN, as shown in Fig. 5 Bioluminescence reaction was activated after mixing, which ensured uniform distribution of FMN in the reaction chamber. To prevent stretching and binding of bioluminescent components to the edge of the channel during immobilization, $0.25 \mathrm{~mm}$ deepening was accomplished under each droplet in the reaction chamber. These improvements resulted in increased reproducibility of chip luminescence intensity measurement by approximately $20 \%$. 


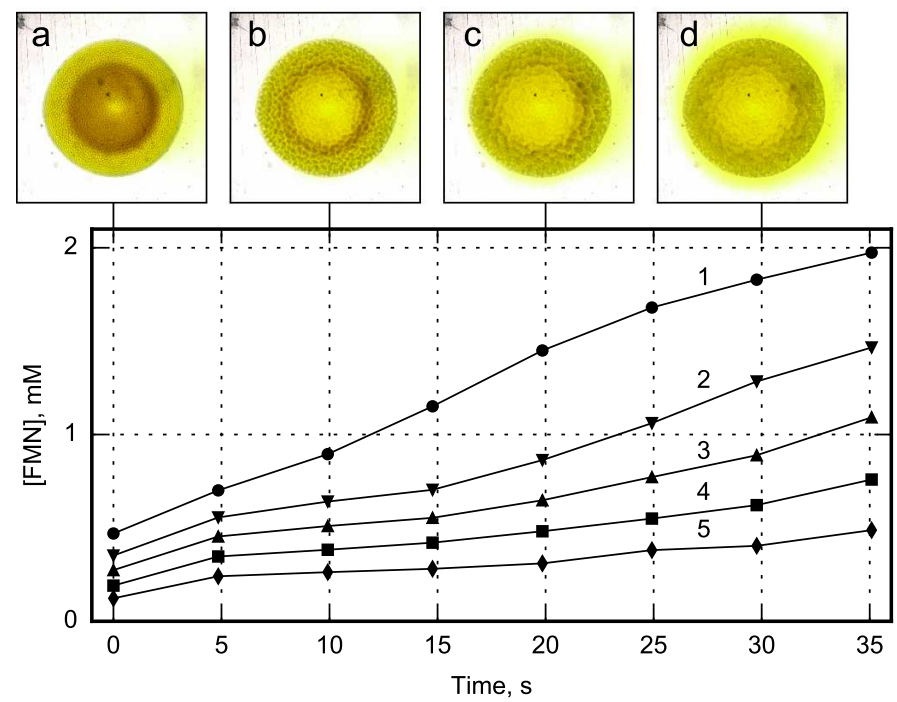

Figure 4: Release of FMN from dried starch droplet. a, b, c, d - images obtained after filling the reaction chamber with the sample at $0,10,20$ and 30 s, respectively; curves on the graph: 1, 2, 3, 4 and 5 show increase of FMN concentration with time on the boundary of dried droplet (1) and at distances of $100,200,300$ and $400 \mu \mathrm{m}$ (curves $2-5$ ), respectively, after sample introduction

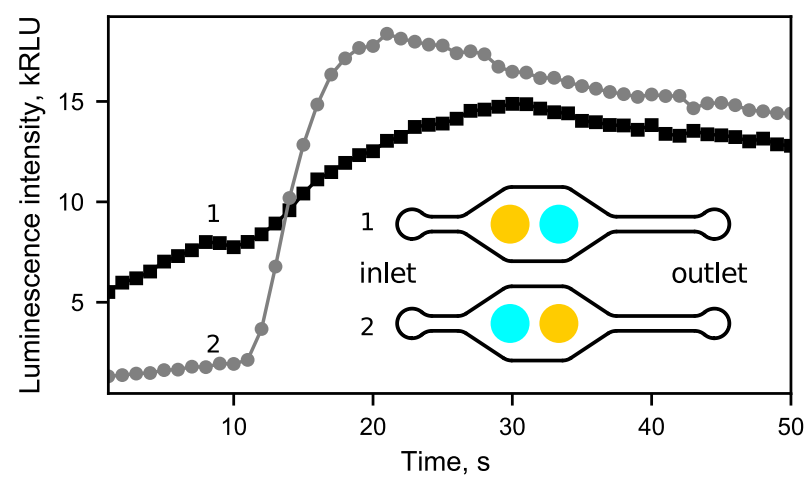

Figure 5: Kinetics of bioluminescence at various locations of FMN (yellow) and enzymes (blue) droplets in the reaction chamber of the chip. Curve $1-$ FMN droplet is located after the inlet of the chip. Curve $2-$ droplet with enzymes is located after the inlet of the chip. Mixing started after $9 \mathrm{~s}$. Premature initiation of reaction was prevented by placing enzyme droplet before FMN droplet in the reaction chamber

\section{Biocompatible low temperature solvent bonding of chips}

Solvent bonding technique was used for sealing PMMA plates. This technique relies on application of chemically reactive organic solvents to solubilize surfaces of parts to be bonded [64]. However, excessive amounts of solvent can cause significant deformation in microfluidic channel geometries. To determine poten- 
tial issues, various pressure values and spraying exposure times were studied during sealing along with solvent types to select optimal parameters for bond strength with less channel deformation.

The effectiveness of solvent used for sealing two parts of the chip can be characterized by the Hildebrand parameter. High similarity of this parameter between the solvent and material results in more effective binding. We used acetone and 1,2-dichloroethane for sealing because Hildebrand solubility parameter of these solvents was the closest to that of PMMA [64].

Sealing of PMMA plates was performed using solvent bonding technique. Optimal thickness of solvent layer was $51 \pm 9 \mu \mathrm{m}$, which was obtained by spraying the solvent for $20 \mathrm{~ms}$. Optimal pressure was estimated as $30 \mathrm{~kg} / \mathrm{cm}^{2}$ for $30 \mathrm{~s}$. At pressures over $30 \mathrm{~kg} / \mathrm{cm}^{2}$, cracks were observed on the chip body. Reducing duration of pressure exposure time led to a decrease in quality of sealing, whereas the increase did not lead to further improvement in sealing quality. These parameters provided sufficient bonding without leakage and prevented channels from deforming and clogging. Results showed that 1,2-dichloroethane provided the same quality of bonding in half the pressure exposure time $(30 \mathrm{~s})$ compared with acetone.

The effect of solvent on components of bioluminescent system was studied. Enzymes and substrates of bioluminescent system were immobilized in the form of discs [69] to test the selected solvents for biocompatibility. These discs were macerated in solvents and then dried and tested to analyze their effects on enzymatic activity. It was shown that 1,2-dichloroethane and acetone exerted insignificant effect on enzyme activity (Fig. 6). This result can be explained by protection of enzymes and substrates provided by starch polymer network. Furthermore, dried starch did not dissolve in 1,2-dichloroethane nor in acetone.

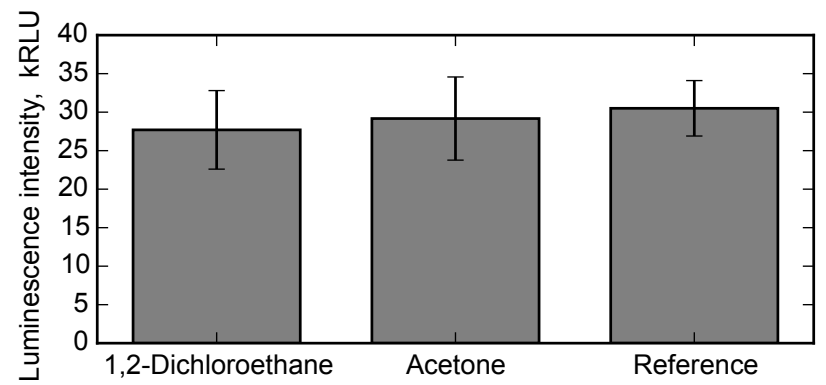

Figure 6: Influence of acetone and 1,2-dichloroethane on bioluminescence intensity of the coupled enzyme system co-immobilized in starch gel with substrates

Chemical bonding can leave traces of organic solvents on microchannel surfaces, which may potentially affect biological components [70]. These traces were observed after superimposing plates under pressure when residual solvent vapor condensed on inner walls of capillaries, collecting inside corners and surface defects. The solvent polished surface before drying (Fig. 7), thus levelling the surface from cutter tracks after milling. Upon complete drying, the polished surface may crack due to resulting surface tension forces. The surface covered with gelatin showed no signs of cracks.

Sealed chip with gelatin scaffold was unsealed and covered with water- 


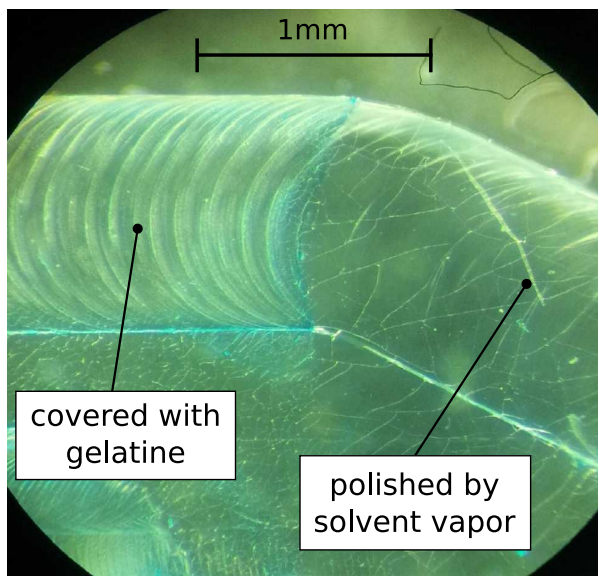

Figure 7: Influence of solvent vapours on the surface of PMMA channel. The surface to the left was coated with gelatin and tinted. Vapor polished the uncoated surface, removing cutter tracks after milling, as can be observed under the gelatin scaffold

soluble dye, which tinted the gelatin. This result indicated strong adhesion of gelatin to PMMA without surface treatment and resistance to solvents. Notably, biological components were immobilized on gelatin surface, protecting them from the potential influence of surface cracks.

\section{Characteristics of chips}

Chips were tested for sensitivity and storage time under various temperatures. Three model pollutants were selected for study: copper(II) sulphate, 1,3-dihydroxybenzene and 1,4-benzoquinone. These compounds represent three typical classes of polluting agents (salts of heavy metals, phenols and quinones) with various mechanisms of their influence on bioluminescent reaction [71,72]: benzoquinone, as an active redox compound, influencing the process of hydrogen transfer; resorcinol mainly inhibits the processes of intermolecular electron transfer; copper cation can effect directly on the enzyme, as well as on electron transfer processes. Among different components of wastewater, phenolic compounds and their oxidation products - quinones have one of the first places in terms of prevalence and harmful effects on water reserviors and their inhabitants [73].

The interaction between immobilized bioluminescent components in the chip and pollutants led to quenching of light emission.

IC $_{50}$ for copper(II) sulphate, 1,3-dihydroxybenzene and 1,4-benzoquinone measured $10 \mu \mathrm{M}, 25 \mathrm{mM}$ and $4 \mu \mathrm{M}$ respectively. LOD for copper(II) sulphate, 1,3-dihydroxybenzene and 1,4-benzoquinone reached $3 \mu \mathrm{M}, 15 \mathrm{mM}$ and $2 \mu \mathrm{M}$ correspondingly (Fig. 8).

Microfluidic chips may be frozen at temperatures down to $-79^{\circ} \mathrm{C}$ without significant loss of activity and sensitivity after defrosting (Fig. 9). Lower storage temperature better retains enzyme activity. Immobilized bioluminescent components retained activity and sensitivity to pollutants for 4 months at $+4{ }^{\circ} \mathrm{C}$ 

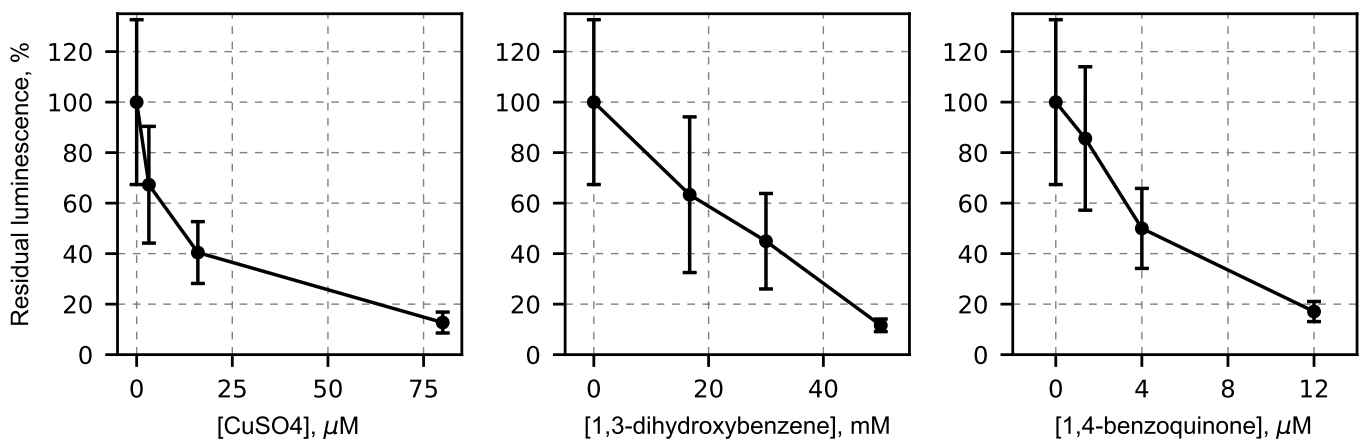

Figure 8: The bioluminescence light intensity in the presence of the model pollutants

and within three weeks when stored at room temperature. The optimal temperature for storage was determined as $-18{ }^{\circ} \mathrm{C}$. This temperature provided extended period of storage and is easy to reach it without special laboratory equipment.
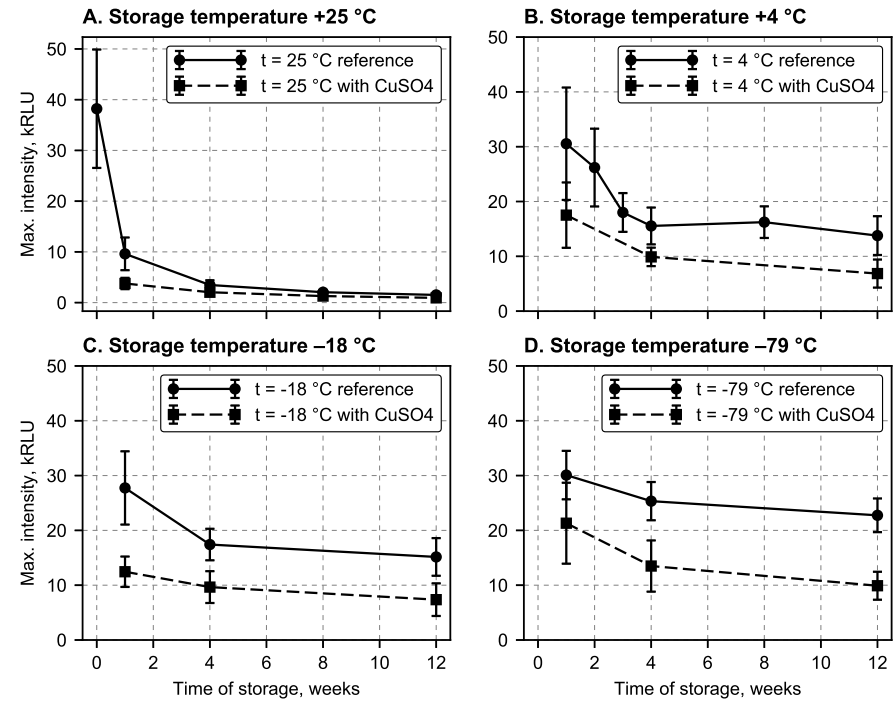

Figure 9: Bioluminescent intensity of the designed microfluidic system stored at different temperatures. Solid line - reference sample, dotted line - sample with $27.5 \mu \mathrm{M}$ of $\mathrm{CuSO}_{4}$

The proposed indication system demonstrates results which are comparable with LOD of copper(II) sulphate $(3 \mu M)$ with traditional lux-biosensors based on bacterial cells $(1 \mu \mathrm{M})$ [30,31]. Additionally, analysis time with disposable microfluidic chips was reduced from $3-5$ h $[30,31,74]$ to $1-3$ min.

Usually, storage time of conventional cell-based biosensors is less than 1 week [12]. Recent advances in the area of applied microbiology have led to increased shelf life of whole-cell biosensors up to a period of several months [7577]. Nevertheless, most of these techniques require availability of expensive equipment and well-trained personnel. Opposite to these requirements, the pro- 
posed disposable enzymatic microfluidic chip is cost-efficient, easy to store and may be handled by staff without special training. Compact design of the chip is suitable with most conventional luminometers with a large cuvette compartment (e.g., Promega GloMax). Altogether, the suggested microfluidic chip is an inexpensive and promising tool for rapid testing of water pollution assessment.

\section{Conclusions}

We suggest the design of luciferase-based microfluidic chip for water pollution assessment (drinking water, waste waters and algal bloom). Automation of bioluminescent bioassay technique in microfluidic chips achieves certain advantages in biotesting. Firstly, analysis time and the number of operations in measurement protocol are reduced due to automation in reagent manipulations while performing enzymatic assay. Secondly, better protection of biological components during analysis and storage is provided. Thirdly, reproducibility of analysis is increased due to the same algorithm of mixing of each chip and fixed location of bioluminescent system relatively to the detector. Finally, sensitivity of the proposed microfluidic chip is comparable with that of traditional cell-based biosensors.

Specific methods of reagents immobilization in plastic microfluidic chips and room temperature solvent bonding of chip plates were developed. The developed methods are safe for immobilized enzymes, inexpensive and easy to scale for mass production.

The proposed microfluidic chip can be one of the rapid and portable components of a test battery [78] indicating pollution of liquid samples, as single bioassays would hardly provide a full picture of environment quality [79, 80].

Further research is aimed to develop a portable luminometer (reader) for the proposed microfluidic chips to obtain inexpensive and easy-to-use handheld device for environmental monitoring.

\section{Acknowledgments}

The authors are grateful to Valentina Kratasyuk for the facilities support and the idea of enzymatic biosensors. We thank Rajeev Ranjan for proofreading of the manuscript.

The research was supported by the grant of the Russian Science Foundation (no.15-19-10041).

\section{References}

[1] Vörösmarty, C.J., McIntyre, P.B., Gessner, M.O., Dudgeon, D., Prusevich, A., Green, P., Glidden, S., Bunn, S.E., Sullivan, C.A., Liermann, C.R., and Davies, P.M. (2010) Nature, 467 (7315), 555-561.

[2] Duan, Q., Lee, J., Liu, Y., Chen, H., and Hu, H. (2016) Bulletin of Environmental Contamination and Toxicology, 97 (3), 303-309. 
[3] Bontidean, I., Mortari, A., Leth, S., Brown, N.L., Karlson, U., Larsen, M.M., Vangronsveld, J., Corbisier, P., and Csöregi, E. (2004) Environmental Pollution, 131 (2), 255-262.

[4] Farré, M. and Barceló, D. (2003) TrAC Trends in Analytical Chemistry, 22 (5), 299-310.

[5] Su, L., Jia, W., Hou, C., and Lei, Y. (2011) Biosensors and Bioelectronics, 26 (5), 1788-1799.

[6] Rajkumar, P., Ramprasath, T., and Selvam, G.S. (2017) in New Pesticides and Soil Sensors, Elsevier, pp. 437-481.

[7] Tüdős, A.J., Besselink, G.A.J., and Schasfoort, R.B.M. (2001) Lab Chip, $1(2), 83-95$.

[8] Luppa, P.B., Müller, C., Schlichtiger, A., and Schlebusch, H. (2011) TrAC Trends in Analytical Chemistry, 30 (6), 887-898.

[9] Ahmed, M.U., Saaem, I., Wu, P.C., and Brown, A.S. (2014) Critical Reviews in Biotechnology, 34 (2), 180-196.

[10] Jung, W., Han, J., Choi, J., and Ahn, C.H. (2015) Microelectronic Engineering, 132, 46-57.

[11] Yoo, E. and Lee, S. (2010) Sensors, 10 (5), 4558-4576.

[12] Cevenini, L., Calabretta, M.M., Tarantino, G., Michelini, E., and Roda, A. (2016) Sensors and Actuators B: Chemical, 225, 249-257.

[13] Berg, B., Cortazar, B., Tseng, D., Ozkan, H., Feng, S., Wei, Q., Chan, R.Y., Burbano, J., Farooqui, Q., Lewinski, M., Di Carlo, D., Garner, O.B., and Ozcan, A. (2015) ACS Nano, 9 (8), 7857-7866.

[14] Modali, A., Vanjari, S.R.K., and Dendukuri, D. (2016) Electroanalysis, 28 (6), 1276-1282.

[15] Kumar, S., Kumar, S., Ali, M.A., Anand, P., Agrawal, V.V., John, R., Maji, S., and Malhotra, B.D. (2013) Biotechnology Journal, 8 (11), 12671279 .

[16] Hu, J., Wang, S., Wang, L., Li, F., Pingguan-Murphy, B., Lu, T.J., and Xu, F. (2014) Biosensors and Bioelectronics, 54, 585-597.

[17] Boyd-Moss, M., Baratchi, S., Di Venere, M., and Khoshmanesh, K. (2016) Lab Chip, 16 (17), 3177-3192.

[18] Wang, L., O’Donoghue, M.B., and Tan, W. (2006) Nanomedicine, 1 (4), 413-426.

[19] da Silva, E.T.S.G., Souto, D.E.P., Barragan, J.T.C., de F. Giarola, J., de Moraes, A.C.M., and Kubota, L.T. (2017) ChemElectroChem, 4 (4), $778-794$. 
[20] Xu, X., Akay, A., Wei, H., Wang, S., Pingguan-Murphy, B., Erlandsson, B., Li, X., Lee, W., Hu, J., Wang, L., and Xu, F. (2015) Proceedings of the IEEE, 103 (2), 236-247.

[21] Kanchi, S., Sabela, M.I., Mdluli, P.S., Inamuddin, and Bisetty, K. (2018) Biosensors and Bioelectronics, 102, 136-149.

[22] Hu, J., Cui, X., Gong, Y., Xu, X., Gao, B., Wen, T., Lu, T.J., and Xu, F. (2016) Biotechnology Advances, 34 (3), 305-320.

[23] Zhu, Y. and Fang, Q. (2013) Analytica Chimica Acta, 787, 24-35.

[24] Kuswandi, B., Nuriman, Huskens, J., and Verboom, W. (2007) Analytica Chimica Acta, 601 (2), 141-155.

[25] Long, F., Zhu, A., and Shi, H. (2013) Sensors, 13 (10), 13928-13948.

[26] Chen, Y., Xianyu, Y., Wu, J., Dong, M., Zheng, W., Sun, J., and Jiang, X. (2017) Analytical Chemistry, 89 (10), 5422-5427.

[27] Roda, A., Guardigli, M., Michelini, E., and Mirasoli, M. (2009) $\operatorname{Tr} A C$ Trends in Analytical Chemistry, 28 (3), 307-322.

[28] Roda, A., Mirasoli, M., Michelini, E., Di Fusco, M., Zangheri, M., Cevenini, L., Roda, B., and Simoni, P. (2016) Biosensors and Bioelectronics, 76, 164-179.

[29] Girotti, S., Ferri, E.N., Fumo, M.G., and Maiolini, E. (2008) Analytica chimica acta, 608 (1), 2-29.

[30] Leth, S., Maltoni, S., Simkus, R., Mattiasson, B., Corbisier, P., Klimant, I., Wolfbeis, O.S., and Csoregi, E. (2002) Electroanalysis, 14 (1), 35.

[31] Hakkila, K., Green, T., Leskinen, P., Ivask, A., Marks, R., and Virta, M. (2004) Journal of Applied Toxicology, 24 (5), 333-342.

[32] Charrier, T., Chapeau, C., Bendria, L., Picart, P., Daniel, P., and Thouand, G. (2011) Analytical and Bioanalytical Chemistry, 400 (4), 1061-1070.

[33] Hastings, J. and Nealson, K. (1977) Annual Reviews in Microbiology, 31, $549-595$.

[34] Esimbekova, E.N., Kondik, A.M., and Kratasyuk, V.A. (2013) Environmental Monitoring and Assessment, 185 (7), 5909-5916.

[35] Esimbekova, E., Kratasyuk, V., and Shimomura, O. (2014) in Bioluminescence: Fundamentals and Applications in Biotechnology - Volume 1, vol. 144, Springer Berlin Heidelberg, Berlin, Heidelberg, pp. 67-109.

[36] Petushkov, V., Kratasyuk, G., Rodionova, N., Fish, A., and Belobrov, P. (1984) Biochemistry Acad. Sci. USSR, 49 (4), 593-604.

[37] Kratasyuk, V.A., Esimbekova, E.N., Gladyshev, M.I., Khromichek, E.B., Kuznetsov, A.M., and Ivanova, E.A. (2001) Chemosphere, 42 (8), 909-915. 
[38] Vetrova, E., Esimbekova, E., Remmel, N., Kotova, S., Beloskov, N., Kratasyuk, V., and Gitelson, I. (2007) Luminescence : the journal of biological and chemical luminescence, 22 (3), 206-14.

[39] Kudryasheva, N.S., Kudinova, I.Y., Esimbekova, E.N., Kratasyuk, V.A., and Stom, D.I. (1999) Chemosphere, 38 (4), 751-758.

[40] Tarasova, A., Kislan, S., Fedorova, E., Kuznetsov, A., Mogilnaya, O., Stom, D., and Kudryasheva, N. (2012) Journal of Photochemistry and Photobiology B: Biology, 117, 164-170.

[41] Esimbekova, E.N., Nemtseva, E.V., Bezrukikh, A.E., Jukova, G.V., Lisitsa, A.E., Lonshakova-Mukina, V.I., Rimatskaya, N.V., Sutormin, O.S., and Kratasyuk, V.A. (2017) Toxicology in Vitro, 45, 128-133.

[42] Kratasyuk, V.A. and Esimbekova, E.N. (2015) Combinatorial chemistry \& high throughput screening, 18 (10), 952-959.

[43] Kudryasheva, N., Kratasyuk, V., and Belobrov, P. (1994) Analytical letters, 27 (15), 37-41.

[44] Denisov, I.A. (2017) Sensors and Actuators B: Chemical, 242, 653-657.

[45] Gautier, S.M., Blum, L.J., and Coulet, P.R. (1991) Analytica Chimica Acta, 255 (2), 253-258.

[46] Lee, Y., Jablonski, I., and DeLuca, M. (1977) Analytical biochemistry, 80 (2), 496-501.

[47] Carrea, G., Bovara, R., Mazzola, G., Girotti, S., Roda, A., and Ghini, S. (1986) Analytical chemistry, 58 (2), 331-333.

[48] Sassolas, A., Blum, L.J., and Leca-Bouvier, B.D. (2012) Biotechnology Advances, 30 (3), 489-511.

[49] Brena, B., González-Pombo, P., and Batista-Viera, F. (2013) in Immobilization of Enzymes and Cells, vol. 1051 (ed. J.M. Guisan), Humana Press, Totowa, NJ, pp. 15-31.

[50] Esimbekova, E., Kratasyuk, V., and Torgashina, I. (2007) Enzyme and Microbial Technology, 40 (2), 343-346.

[51] Bezrukikh, A., Esimbekova, E., Nemtseva, E., Kratasyuk, V., and Shimomura, O. (2014) Analytical and Bioanalytical Chemistry, 406 (23), $5743-5747$.

[52] Lonshakova-Mukina, V., Esimbekova, E., and Kratasyuk, V. (2015) Sensors and Actuators B: Chemical, 213, 244-247.

[53] Ahn, C., Choi, J., Beaucage, G., Nevin, J., Lee, J., Puntambekar, A., and Lee, R. (2004) Proceedings of the IEEE, 92 (1), 154-173.

[54] Fiorini, G.S. and Chiu, D.T. (2005) BioTechniques, 38 (3), 429-446.

[55] Ren, K., Zhou, J., and Wu, H. (2013) Accounts of Chemical Research, 46 (11), 2396-2406. 
[56] Tian, W. and Finehout, E. (2008) Microfluidics for Biological Applications, vol. 49, Springer.

[57] Sollier, E., Murray, C., Maoddi, P., and Di Carlo, D. (2011) Lab on a chip.

[58] Anderson, J.R., Chiu, D.T., Wu, H., Schueller, O.J., and Whitesides, G.M. (2000) Electrophoresis, 21 (1), 27-40.

[59] McDonald, J.C. and Whitesides, G.M. (2002) Accounts of Chemical Research, 35 (7), 491-499.

[60] Becker, H. and Locascio, L.E. (2002) Talanta, 56 (2), 267-287.

[61] Boone, T.D., Fan, Z.H., Hooper, H.H., Ricco, A.J., Tan, H., and Williams, S.J. (2002) Peer reviewed: plastic advances microfluidic devices, ACS Publications.

[62] Guckenberger, D.J., de Groot, T.E., Wan, A.M.D., Beebe, D.J., and Young, E.W.K. (2015) Lab Chip, 15 (11), 2364-2378.

[63] Zhu, X., Liu, G., Guo, Y., and Tian, Y. (2006) Microsystem Technologies, 13 (3-4), 403-407.

[64] Tsao, C. and DeVoe, D.L. (2009) Microfluidics and Nanofluidics, 6 (1), $1-16$.

[65] Brown, L., Koerner, T., Horton, J.H., and Oleschuk, R.D. (2006) Lab on a chip, 6 (1), 66-73.

[66] Lukyanenko, K.A., Belousov, K.I., Denisov, I.A., Yakimov, A.S., Esimbekova, E.N., Bukatin, A.S., Evstrapov, A.A., and Belobrov, P.I. (2017) Micro \& Nano Letters, 12 (6), 377-381.

[67] Lukyanenko, K.A., Denisov, I.A., Yakimov, A.S., Esimbekova, E.N., Belousov, K.I., Bukatin, A.S., Kukhtevich, I.V., Sorokin, V.V., Evstrapov, A.A., and Belobrov, P.I. (2017) Applied Biochemistry and Microbiology, 53 (7), $775-780$.

[68] Lukyanenko, K.A., Denisov, I.A., Yakimov, A.S., Esimbekova, E.N., Belousov, K.I., Bukatin, A.S., Kukhtevich, I.V., Sorokin, V.V., Evstrapov, A.A., and Belobrov, P.I. (2016) Biotechnology in Russia, 32 (5), 69-76.

[69] Esimbekova, E.N., Lonshakova-Mukina, V.I., Bezrukikh, A.E., and Kratasyuk, V.A. (2015) Doklady Biochemistry and Biophysics, 461 (1), 102 105.

[70] Berthier, J. and Brakke, K.A. (2012) The physics of microdroplets, John Wiley \& Sons, Inc ; Scrivener Publishing LLC, Hoboken, New Jersey : Salem, Massachusetts.

[71] Kudryasheva, N., Shalaeva, E., Esimbekova, E., Kratasyuk, V., Balayan, A., and Stom, D. (1994) Biophysics, 39 (3), 441-451.

[72] Kudryasheva, N.S. (2006) Journal of Photochemistry and Photobiology B: Biology, 83 (1), 77-86. 
[73] Stom, D.J. (1977) Acta Hydrochimica et Hydrobiologica, 5 (3), 291-298.

[74] Yagur-Kroll, S., Lalush, C., Rosen, R., Bachar, N., Moskovitz, Y., and Belkin, S. (2014) Applied Microbiology and Biotechnology, 98 (2), 885895.

[75] Michelini, E. and Roda, A. (2012) Analytical and Bioanalytical Chemistry, 402 (5), 1785-1797.

[76] Date, A., Pasini, P., and Daunert, S. (2007) Analytical Chemistry, 79 (24), 9391-9397.

[77] Yagur-Kroll, S., Schreuder, E., Ingham, C.J., Heideman, R., Rosen, R., and Belkin, S. (2015) Biosensors and Bioelectronics, 64, 625-632.

[78] Davoren, M., Ní Shúilleabháin, S., Halloran, J., Hartl, M., Sheehan, D., O'Brien, N., van Pelt, F., and Mothersill, C. (2005) Ecotoxicology, 14 (7), 741-755.

[79] Bierkens, J., Klein, G., Corbisier, P., Van Den Heuvel, R., Verschaeve, L., Weltens, R., and Schoeters, G. (1998) Chemosphere, 37 (14-15), 29352947.

[80] Repetto, G., Jos, A., Hazen, M.J., Molero, M.L., Del Peso, A., Salguero, M., Del Castillo, P., Rodriguez-Vicente, M.C., and Repetto, M. (2001) Toxicology in Vitro, 15 (4), 503-509. 